\title{
Exploración de las percepciones infantiles ante desastres naturales (huracanes): estudio de niños en Granada
}

\section{Exploring children's perceptions of natural disasters (hurricanes): A study of children in Grenada}

\author{
LORITA JOSEPH \\ Lorita Joseph es alumna de Doctorado en la Unidad de Trabajo Social de la Universidad de las Antillas, San Agustín, Trinidad. \\ Se desempeña como trabajadora social en el cargo de orientadora en el Ministerio de Educación, en la División de Servicios de \\ Apoyo Estudiantil. Correo electrónico: designersoriginal@yahoo.com. Dirección postal: 328, Papourie Road, Diamond Village, San \\ Fernando, Trinidad.
}

\begin{abstract}
Resumen
Este artículo se centra en las experiencias relativas a un huracán de dieciocho niños de Granada. Si bien se ha estudiado de manera extensa el estrés y las maneras en que los adultos enfrentan este tipo de desastres, poco se sabe acerca de los niños con respecto a este tema, en particular en la región del Caribe. Utilizando los marcos de Investigación-Acción, Teoría Fundamentada y Metodologias de Investigación Centradas en el Niño, en este estudio cualitativo se emplearon los juegos y procesos de Teatro en Educación para ayudar a que los niños utilizaran el "lenguaje" innato del teatro para revelar, explorar y expandir su conocimiento acerca de sus percepciones y experiencias relativas a la vivencia de un desastre natural. La información recabada de las perspectivas de los niños resulta importante para comprender cómo viven los desastres naturales $y_{\text {, }}$ más aun, para que dicha información se utilice en el desarrollo de respuestas en políticas y programas que son relevantes considerando las características de los niños y niñas y sus contextos especificos. En la investigación se descubrió que los niños/as son increiblemente resilientes y que suelen buscar elementos dentro de su propio ambiente para lidiar con situaciones de esa naturaleza. Existen diversas implicancias para la práctica y la investigación, que incluyen reconocer las fortalezas de los niños y aceptar sus experiencias como válidas.
\end{abstract}

Palabras claves. Desastres naturales, niño/niños, resiliencia, normalidad, percepción, preparación.

\begin{abstract}
This article focuses on the hurricane experiences of eighteen children from Grenada. While stress and the ways in which adults cope with it has received much attention, little is known about children in this area, especially within the Caribbean region. Using the frameworks of Action Research, Grounded Theory and Child Centered Research Methodologies, this qualitative study used the games and processes of Drama-in-Education to help children to use their innate "language" of drama and dramatic play to disclose, explore and expand their understanding of their perceptions and experiences around living through a natural disaster. Information from children's perspectives is important in understanding how they experience natural disasters and further, to use that information to develop policy and programmatic responses that are relevant to children's geographies and specific to their contexts. The study found that children are amazingly resilient and often draw on elements within their environment in finding ways to cope. There are several implications for practice and research which include recognizing children's strengths and understanding their experiences as having validity.
\end{abstract}

Keywords. Natural disasters, child/children, resilience, normalcy, perception, preparedness. 


\section{Introducción}

Abraham Lincoln dijo una vez: "Un niño es una persona que continuará lo que tú comenzaste. Se sentará donde estás sentado tú ahora, y cuando te marches; se preocupará de aquellas cosas que tú consideras importantes. Puedes adoptar todas las políticas que desees pero la manera en que se lleven a cabo depende de él. Él tomará el control de nuestras ciudades, iglesias, escuelas, universidades y empresas... El destino de la humanidad está en sus manos". Esta declaración del Presidente Lincoln debería ser un argumento convincente para hacer intervenciones con aquellos niños* que han sido víctimas o testigos de eventos traumáticos. Las experiencias traumáticas en la infancia determinan la manera en que los niños ven el mundo, especialmente en cuanto a seguridad, riesgo, daño, pérdida, protección e intervención, y pueden tener una influencia en las expectativas de recurrencia de amenazas, de una falta de intervenciones protectoras y/o de impotencia, que pueden regir la vida y el comportamiento de un niño.

Cuando las personas se convierten en víctimas de desastres naturales, sus vidas pueden volcarse en diversos niveles. Además del evidente daño físico y de las consecuencias económicas, las personas pueden quedar con profundas heridas emocionales y psicológicas que pueden tardar años en sanar. En septiembre de 2004, el huracán más fuerte que había azotado al Caribe en la última década, dejó a la isla de Granada totalmente devastada. El Huracán Iván, de categoría 4, golpeó Granada con vientos sostenidos de $185 \mathrm{~km} / \mathrm{hora}$. Cuando terminó el desastre, treinta y siete personas habían muerto, el noventa por ciento de las viviendas de Granada estaba en ruinas; la gente perdió sus pertenencias y su sustento. Miles quedaron sin agua, electricidad y servicios telefónicos, y había una escasez de alimentos. Además, diversos saqueos de locales comerciales y hogares desprotegidos exacerbaron una situación que ya era dramática.

Ubicada en el Caribe, Granada forma parte del Archipiélago de las Antillas y es la más sureña de las Islas de Barlovento. El país consiste en la isla principal de Granada y dos islas Granadinas, Petite Martinique y Carriacou. La población estimada de Granada es de 100.000 personas y el país vive de la exportación de nuez moscada, plátanos y cacao, además del turismo. Con un área de 214 kilómetros cuadrados, Granada se ubica en un cinturón de hu- racanes y tiene una temporada de huracanes entre junio y noviembre. A medida que continúa el cambio climático, la vulnerabilidad de Granada ante los huracanes aumenta y, tal como quedó demostrado con Iván, en menos de ocho horas la infraestructura socioeconómica vital del país, incluyendo viviendas, servicios públicos, instalaciones turísticas y la producción agrícola comercial y de subsistencia sufrieron daños incalculables.

Durante los meses posteriores al desastre, la población de Granada intentó lidiar con los efectos traumáticos del Huracán Iván. La gente se vio forzada a alojar con familiares y amigos, algunos debieron vivir en improvisados refugios de lona y otros intentaron recuperar su sustento. En ese momento, un porcentaje importante de la población de Granada eran niños. Los niños son particularmente vulnerables a las situaciones altamente estresantes y traumáticas relacionadas con desastres y sus consecuencias. Los traumas pueden abrumar el sentido de control, de conexión y de vida en un niño. Pueden causarle miedo, impotencia y aislamiento. Pueden interferir en la habilidad que tiene un niño para desarrollar un sentido de equilibrio funcional con el mundo y pueden poner en peligro su sentido de seguridad y protección.

\section{Discusión conceptual}

De acuerdo a Brock, Lazarus y Jimerson (2002: 435-450), los desastres naturales pueden ser particularmente traumáticos para niños y jóvenes. Pueden resquebrajar el sentido de seguridad y normalidad de un niño, porque usualmente toda su comunidad ha sufrido el mismo impacto y existe la necesidad de reubicarlos cuando su hogar y/o su comunidad han sido destruidos. Estas experiencias pueden tener como resultado una variedad de temas particulares y problemas para hacer frente a la situación, lo que puede poner a prueba la capacidad que tiene la familia para disminuir o aumentar el trauma, las reacciones emocionales y las técnicas para enfrentar el problema.

Haciendo referencia específica a los huracanes, Brock et al señalan que "por lo general, los huracanes se predicen con días o incluso semanas de anticipación, dando a las comunidades... y a las familias tiempo para abastecerse y así estar preparados. Sin embargo, al mismo tiempo estas actividades pueden generar temor y ansiedad. Si bien es posible advertir a las comunidades acerca de un posible riesgo,

\footnotetext{
* En este artículo se usará genéricamente niño o niña, para referirnos tanto a niños como a niñas. N.E.
} 
siempre existe incertidumbre con respecto a la ubicación exacta donde golpeará el huracán. Cuando lo hace, las víctimas son testigos de intensos truenos, lluvias, relámpagos y vientos, de modo que pueden existir reacciones agudas de miedo durante los meses siguientes. Tormentas posteriores pueden gatillar reacciones de pánico en algunos niños. Entre las reacciones inmediatas a un huracán se encuentra un agotamiento emocional y físico. En algunos casos, los niños pueden sufrir de culpabilidad del sobreviviente (por ejemplo, debido a que ellos no sufrieron daño, mientras otros resultaron heridos o muertos)".

El impacto de los desastres naturales va más allá de los efectos físicos, que suelen derivar en diversos tipos de estrés, a nivel tanto social como psicológico. De acuerdo a algunos estudios en los que se analiza el impacto de desastres naturales en niños y adolescentes, existen consecuencias emocionales y conductuales negativas en diversos grados. Las investigaciones han demostrado que cuando un niño se ve expuesto a un evento traumático, sus características individuales, su acceso a asistencia social, los acontecimientos de su vida y su estilo de enfrentar el problema tienen un impacto en la respuesta al estrés del niño. La intensidad de sus reacciones dependerá de factores de riesgo como la exposición al acontecimiento en sí, lesiones propias o la pérdida de un ser querido, el nivel de apoyo de sus padres o tutores, la separación de su hogar o comunidad, el nivel de destrucción física y riesgos preexistentes, como una experiencia traumática previa o una enfermedad mental (La Greca, Silverman, Vernberg y Prinstein;1996: 712-723; Brock, Lazarus y Jimerson; 2002: 435-450).

Incluso si no han resultado heridos físicamente durante un desastre, la respuesta emocional de los niños puede ser intensa. Pueden irritarse fácilmente, volverse emocionalmente dependientes y apegados, o distantes y reservados. Si bien son pequeños y parecen no comprender lo que sucede, los niños se ven afectados tanto como los adultos. Las reacciones a un trauma pueden surgir inmediatamente tras el evento traumático o días y semanas más tarde, y la respuesta al trauma por lo general depende de la edad del niño. De acuerdo a Henahan (2001), "los niños en edad escolar tienen la capacidad de comprender la permanencia de una pérdida a partir de un trauma... ya que su pensamiento es más maduro [que los preescolares], su comprensión del desastre es más completa”. Los niños en edad escolar pueden volverse más retraídos o agresivos, y pueden verse particularmente afectados por la pérdida de objetos que atesoraban o de sus mascotas. De acuerdo a las Directrices para la Educación en Situaciones de Emergencia y Crisis de UNESCO, las reacciones de los niños a esta edad pueden clasificarse en tres categorías: Regresivas, Emocionales/Conductuales y Fisiológicas.

TABLA I

CATEGORÍAS DE REACCIONES DE NIÑOS A TRAUMAS EN BASE A LAS DIRECTRICES PARA LA EDUCACIÓN EN SITUACIONES DE EMERGENCIA Y CRISIS DE UNESCO

\begin{tabular}{|c|c|c|}
\hline Reacciones regresivas & $\begin{array}{l}\text { Reacciones } \\
\text { emocionales/conductuales }\end{array}$ & Reacciones fisiológicas \\
\hline $\begin{array}{l}\text { - Creciente competencia con } \\
\text { hermanos menores } \\
\text { - Apego excesivo } \\
\text { - Llantos o quejidos } \\
\text { - Deseo de ser alimentados o } \\
\text { vestidos } \\
\text { - Regreso a hábitos que habían } \\
\text { abandonado }\end{array}$ & $\begin{array}{l}\text { - Fobia escolar } \\
\text { - } \text { - y amiraimiento de grupos de juego } \\
\text { - Retraimiento de contacto familiar } \\
\text { - Irritabilidad } \\
\text { - Desobediencia } \\
\text { - Temor al viento, lluvia, etc. } \\
\text { - Incapacidad de concentración } \\
\text { y disminución del rendimiento } \\
\text { escolar } \\
\text { - Comportamiento agresivo } \\
\text { - Conversaciones repetitivas acerca } \\
\text { de sus experiencias } \\
\text { - Tristeza por pérdidas } \\
\text { - Sobre-reacción a crisis o cambios } \\
\text { en el ambiente }\end{array}$ & $\begin{array}{l}\text { - } \\
\text { - } \\
\text { o auditivos } \\
\text { - } \quad \text { Picazónyros por problemas visuales } \\
\text { - } \quad \text { Náuseas } \\
\text { - } \quad \text { Alteraciones de sueño, } \\
\text { pesadillas }\end{array}$ \\
\hline
\end{tabular}




\section{Los niños y la resiliencia}

Los niños son sorprendentemente flexibles, a pesar de que pueden verse afectados profundamente por un trauma. Parecen tener una capacidad innata para ser resilientes; para resistir o recuperarse de las adversidades. Norman (2003: 3) define la resiliencia como "la capacidad de recuperarse ante condiciones adversas o adaptarse exitosamente a ellas". De acuerdo a la autora, la resiliencia se debe a la "interacción de dos condiciones: factores de riesgo -acontecimientos estresantes o condiciones ambientales adversas que aumentan la vulnerabilidad de los individuos- y la presencia de factores protectores personales, familiares y comunitarios que moderan las vulnerabilidades y los protegen contra ellas". Por tanto, resulta importante estudiar la interacción entre la experiencia que viven los niños ante un huracán (factor de riesgo) y la presencia de características/dinámicas personales, familiares y comunitarias (factores protectores), con el fin de determinar si esto los ha ayudado a mejorar su resiliencia durante el período de trauma.

Los niños resilientes demuestran una adaptación y un ajuste positivos en condiciones en las que podría esperarse que ocurriera un fracaso considerable de las capacidades para lidiar con la situación, debido a niveles inusuales de estrés. Los niños resilientes exhiben de manera consistente una perspectiva optimista, auto-eficacia, auto-disciplina, habilidades para resolver problemas y relaciones de crianza sostenidas. De acuerdo a Goldman (2004), entre las señales de que se está frente a un niño resiliente se encuentran la habilidad para recuperarse, la capacidad de tener valor, la disposición a conversar acerca de sus sentimientos, el don de la risa, la motivación para salir adelante y la capacidad de pedir ayuda.

Es importante señalar que Goldman y otros autores que hacen mención a la resilencia escriben desde perspectivas occidentales, y que estas señales o indicadores de resiliencia pueden variar dentro de una sociedad caribeña, en base a diferencias culturales, religiosas y sociales. Por ejemplo, Goldman postula que una señal de un niño resiliente es la disposición a conversar acerca de sus sentimientos. No obstante, esto puede resultar difícil en sociedades caribeñas, donde el axioma "los niños deben verse y no escucharse" es un modo de vida arraigado y es, por lo general, muy difícil para los niños tener un espacio para conversar o compartir. En esas sociedades, los niños aprenden a permanecer callados y es posible que no siempre estén dispuestos a conversar. Es por ello que la falta de disposición a conversar por parte de esos niños puede no ser una señal de vulnerabilidad o una falta de resiliencia, sino un indicador de socialización y de conductas aprendidas.

\section{Metodología}

En esta investigación cualitativa se utilizaron técnicas de Teatro en Educación para explorar las percepciones de los niños frente a desastres naturales (huracanes). Los principales objetivos fueron:

1. Investigar las percepciones de desastres naturales desde la perspectiva de niños.

2. Explorar los significados que los niños dan al concepto de preparación para desastres.

3. Mejorar la resiliencia en los niños.

4. Dar a los niños una voz.

En el estudio participaron dieciocho niños: 14 niñas y 4 niños de entre nueve (9) y once (11) años, provenientes de diversos contextos socioeconómicos. La investigación se realizó respetando por completo los derechos del niño y cumpliendo con los procedimientos éticos de la Universidad de las Antillas.

\section{Análisis y hallazgos}

Se realizó un análisis temático de la información, estudiando algunos de los temas principales basados en los objetivos y la bibliografía, además de temas nuevos que emergieron en el estudio.

\section{Percepciones}

Los niños en esta investigación tenían gran claridad en su comprensión y articulación de un desastre natural y un huracán como algo que causaba daño/era destructivo. A la hora de definir un desastre natural, solieron dar ejemplos de sus distintos tipos, por ejemplo, huracanes, tornados, tormentas, volcanes, salidas de mar e inundaciones. Sin embargo, estos ejemplos iban acompañados de descripciones de destrucción que incluían la muerte de personas, la destrucción de casas y edificios, la destrucción de aldeas y comunidades, la caída de postes de electricidad y árboles y la caída de techumbres. Además de describir un huracán mediante las características de vientos fuertes y lluvia, los niños lo vieron como un fenómeno causado por Dios y, de hecho, un niño lo describió como "algo que mata a las personas por todas las cosas malas", mientras otro dijo que era "algo que hace Dios para demostrarle a las personas que Él nos creó". 


\section{Experiencias}

El $100 \%$ de la muestra provino de los dos sectores más fuertemente golpeados durante el Huracán Iván y, como resultado, vieron y vivieron gran parte de la destrucción que ocurrió. Cuando se les pidió que describieran qué los había asustado más acerca de Iván, al menos un 80\% escribió acerca del daño que habían visto y vivido, además de la pérdida de familiares, amigos, mascotas y pertenencias (como juguetes y ropa) o la posibilidad de perderlos. La intensidad del impacto de esta experiencia; haber visto la destrucción, haber perdido a seres queridos y haber vivido en primera persona las dificultades a la hora de la reconstrucción y la vuelta a la normalidad, parecieron traducirse en una preocupación por las personas a su alrededor. Cuando llegó el Huracán Emily (9 meses después de el Huracán Iván), la preocupación de los niños giraba en torno al bienestar de los demás, que incluía ancianos, mujeres embarazadas, personas sin hogar y otros que aun se encontraban en el proceso de reconstruir sus casas y vivían en estructuras no terminadas.

\section{Sentimientos}

El miedo fue el sentimiento más mencionado y discutido en este estudio. Los niños expresaron tener miedo en torno a diversos elementos de su experiencia.

1. La llegada de Iván: Si bien ninguno de ellos había vivido un huracán antes, el haber escuchado historias del Huracán Janet, que golpeó Granada en 1955, además de haber visto las emociones (miedo y ansiedad) de algunos de los adultos en su ambiente, sirvieron para crear una sensación de miedo en los niños. Muchos de ellos mencionaron este miedo como pensar en que morirían. La presencia de vientos fuertes y lluvia abundante antes de la llegada de Iván también exacerbó este miedo. Para algunos, este miedo se vio realzado con la llegada del Huracán Emily.

2. Falta de conocimiento y lugares seguros: Muchas familias desconocían la ubicación de albergues u otros lugares seguros a los que podían acceder antes, durante o después del Huracán Iván. Había muy pocos albergues designados y muy poca información acerca de los mismos antes del Huracán Iván. De ese modo, las familias debieron crear "lugares seguros" durante el Huracán Iván, como por ejemplo "escondiéndose en el baño, escondiéndose bajo la cama, escondiéndose bajo una mesa, yendo a la parte baja/subterráneo de la casa, quedándose en el pasillo, durmiendo en el auto". Además, el "lugar seguro" de algunos albergues resultó no ser muy seguro, ya que muchos albergues sufrieron la pérdida de sus techos y se inundaron. Esta situación fue aun más grave con la llegada del Huracán Emily, ya que no solo persistía la escasez de información acerca de los albergues, sino que la mayoría de los edificios designados como albergues no estaban listos para su uso.

3. Fenómenos climáticos: El viento, los truenos, la lluvia y los relámpagos sirvieron para aumentar aun más el miedo durante ambos huracanes. Los niños mencionaron el sonido del viento mientras se arremolinaba alrededor de las casas, levantaba los techos y avanzaba rápidamente dentro de algunos hogares. De hecho, la "realidad" de vivir el viento, en especial durante el Huracán Iván, podía sentirse en los relatos de los niños y su convicción de haber "visto" el viento. El 100\% de los niños que vivieron el Huracán Iván dijeron haberse sentido aterrados y atemorizados por el fenómeno.

\section{Normalidad}

En el contexto de esta investigación, se definió la normalidad como la existencia de constantes en la vida de un niño. Estas constantes incluían la familia y la presencia de la familia, los espacios familiares y las rutinas. La normalidad involucraba aquellas cosas que eran predecibles acerca de la vida de un niño y que les permitía predecir el mañana en base al hoy.

Un número considerable de niños vivió una pérdida de la normalidad en sus vidas por diversos medios:

- Muerte de un familiar o amigo

- Pérdida de una mascota

- Pérdida de pertenencias

\section{- Pérdida de/Daño a su hogar}

Cuando se les preguntó qué los entristecía más acerca de sus experiencias, los niños mencionaron en su mayoría el extenso daño del que fueron testigos, la pérdida de mascotas, juguetes, seres queridos y lugares. Algunos niños lo explicaron como "ya nada parecía normal". Esta pérdida de normalidad significaba que sus vidas diarias se habían transformado, muy pocas cosas eran predecibles y la existencia de constantes como los lugares para vivir, la presencia de seres queridos/familia, las posesiones más atesoradas y las rutinas parecieron haber sido arrasadas con un solo acontecimiento.

El regreso a la normalidad fue el indicador de/res- 
puesta a lo que hacía más felices a los niños en el contexto de sus experiencias frente al huracán. Algunos niños mencionaron su felicidad a nivel personal, por ejemplo, haber recibido mascotas o juguetes nuevos, haber visto cómo sus casas se reconstruían y haber podido regresar a sus hogares, haber obtenido una casa nueva y haber podido estar con sus familias y sus amigos nuevamente. La pérdida de espacios y, de manera más específica, espacios de vida, pereció haber tenido un impacto importante en muchos de los niños que debieron abandonar sus hogares debido a que resultaron dañados o destruidos. Comentaron con gran tristeza el haber tenido que dejar a sus familiares cercanos para irse a vivir con parientes o, muchas veces, el problema que significó para sus familias el tener que buscar casas para arrendar o tener que compartir viviendas con vecinos y amigos. Otros hablaron acerca de su felicidad a un nivel más amplio, por ejemplo, "Yo fui más feliz que nunca cuando reconstruyeron Granada. Fui más feliz que nunca cuando todo volvió a la normalidad y Granada comenzó a surgir nuevamente".

\section{Resiliencia}

La resiliencia de los niños se hizo muy evidente desde dos puntos de vista:

1. Sus respuestas afectivas actuales ante fenómenos climáticos (viento, lluvia y truenos) y su racionalización de estas respuestas.

2. Su cognición con respecto a qué es lo mejor que se puede hacer ante un huracán y qué actos cambiarían sobre sus experiencias ante el huracán.

Como se mencionó anteriormente, el 100\% de la muestra y el 74\% de la muestra dijeron haberse sentido aterrados por el viento, la lluvia y los truenos durante el Huracán Iván y el Huracán Emily, respectivamente. Un $60 \%$ de la muestra admitió aun sentir miedo ante estos fenómenos después de Iván. Sin embargo, esta cifra descendió a un 40\% de su respuesta actual de miedo (después de Emily). Las explicaciones de la reducción en este factor de miedo y un aumento correlacionado en sentirse bien, seguros, y no sentir miedo envuelven la racionalización de los niños de que ya han vivido dos huracanes, saben cómo suena el viento y la lluvia en esos momentos en comparación al modo en que suenan ahora. Es por ello que pueden suponer que no vendrá otro huracán (la evaluación de los factores de riesgo y la evaluación realista del medioambiente por parte de los niños) y se embarcan en un distanciamiento adaptativo de su experiencia.
El otro elemento que contribuyó a que sintieran menos miedo fue el estar con la familia o con un miembro de la familia, o en sus escuelas, con sus profesores. Por tanto, la presencia de un ser querido (generalmente un adulto) les otorgó un nivel de protección y seguridad (factores protectores a través del ambiente).

Las experiencias que tuvieron los niños en ambos huracanes han servido para organizar sus percepciones y cogniciones con respecto a qué es lo mejor que puede hacerse para garantizar su propia seguridad. En gran medida, las acciones que emprendieron fueron expresadas en la idea/concepto de preparación. Entre estas estrategias se encontraba la importancia de acudir a un albergue/lugar seguro, escuchar las noticias, recibir información adecuada de antemano y animar a sus familias a que protejan sus pertenencias, empacar, aprovisionarse de alimentos y agua y tener a mano un equipo de emergencia. Los niños también mencionaron el permanecer en calma / no dejarse llevar por el pánico, mantenerse en contacto con la familia y los amigos, y trabajar en equipo como elementos importantes que ayudarán a su bienestar en caso de que ocurra algún desastre.

\section{Preparación}

Muchas familias tenían la idea de que "Dios era Granadino" y los cuidaría. Los niños admitieron que por lo general sus familias no estuvieron bien preparadas para ninguno de los dos huracanes. Sin embargo, hubo un acuerdo generalizado en el hecho de que las medidas de seguridad tenían que ver con la preparación, por ejemplo, "entablar o encintar las ventanas, tener un equipo de emergencia, aprovisionarse de alimentos y agua y proteger documentos importantes". Es por ello que hubo un alto nivel de cognición acerca de cómo estar preparados se traducía en estar seguros. Los niños también comprendieron por qué era importante tener un equipo de emergencia y qué tipo de elementos era necesario tener en dicho equipo. En un ejercicio en el que debían empacar un equipo imaginario de emergencia, algunos de los elementos que se incluyeron fueron vendas, toallitas con alcohol, una linterna, pilas, algodón, bolsas de basura, clavos, un martillo, alcohol, un cuchillo, folletos informativos, agua, un abrelatas y una radio, por mencionar algunos. Un niño incluyó lasaña y otro agregó chocolate. Durante la discusión, los niños señalaron que esos alimentos no durarían mucho y que tal vez deberían comérselos de inmediato. Esto demostró comprensión acerca de productos pere- 
cibles y no perecibles y se llegó a una conversación al respecto. Sin embargo, tal vez apunta a algo más fundamental para los niños y la preparación ante desastres. Para los adultos, la lasaña y el chocolate pueden parecer inapropiados y absurdos para incluir en un equipo de emergencia; no obstante, lo que estos niños probablemente querían decir es que al prepararse para un desastre es importante que ellos tengan elementos que los reconforten. Al explorar esos dos alimentos, se descubrió que eran la comida [reconfortante] favorita de estos niños y por tanto, los niños podían estar diciendo que lo que es absurdo para algunos es necesario para ellos, porque los reconforta y les otorga un grado de seguridad. Al unir las ideas de consuelo y seguridad con resiliencia, podemos inferir que este tipo de consuelo/seguridad ayuda a reforzar la resiliencia de un niño y provee la capacidad de lidiar con una situación difícil si el niño tiene el consuelo/seguridad de algo que es importante para él.

Esto demuestra que como adultos debemos mover nuestras perspectivas para conceder espacio a las perspectivas de los niños, ayudándolos a articular lo que es importante para ellos. Además, en cuanto a los niños, la preparación ante desastres y la ayuda para que se sientan seguros, puede ser importante permitir que los niños incluyan un elemento a la lista establecida de preparación ante desastres. Esto les permite escoger aquel elemento que les es beneficioso en términos de duración, grado de consuelo, etc.

\section{Seguridad y familia}

Un 30\% de los niños expresó sentimientos de seguridad/sentirse más seguros una vez que los huracanes habían terminado. Para al menos un 60\% de la muestra, sentirse seguros y sus experiencias de seguridad decían relación con permanecer con sus familias durante las experiencias en los huracanes. Además, un 13\% declaró haberse sentido más seguros cuando estaban escondidos en lugares seguros (en sus casas o en un albergue). No obstante, en la discusión grupal acerca del tema, se mencionó que si bien el estar en un lugar seguro les otorgaba una sensación de bienestar, el elemento decisivo de seguridad se dio al estar en estos lugares con sus familias.

\section{Espiritualidad}

Según los relatos de los niños, Dios apareció como uno de los primeros factores, incluso como una explicación de la razón por la cual ocurrieron los huracanes. Un huracán es un fenómeno de la na- turaleza, pero es Dios quien lo envía. Las razones por las cuales Él los enviaba variaron, pero definitivamente eran obra de Él. Además, de acuerdo a las historias de los niños, solían pedirle orientación y protección a Dios, rezaban y agradecían a Dios por estar vivos.

\section{Padres, profesores, el gobierno y seguridad}

Con respecto a los padres/tutores, el 100\% de la muestra indicó que lo que más necesitaban era consuelo y confianza. Este deseo por sentirse reconfortados se mencionó como "reconfórtame" o "abrázame fuertemente" o "dime que estaré seguro/bien" o "abrázame, quédate a mi lado y dime que me quieres" o "quédate conmigo, quédate cerca y mantenme abrigado y feliz". Esta necesidad también se expresó en términos de medidas directas de seguridad como "me gustaría que me construyeran un albergue" o "me gustaría que me llevaran a un lugar seguro". Las peticiones que los niños hacían a sus profesores eran similares a las que hacían a sus padres: consuelo, confianza y traslado a un lugar seguro. Además, los niños pidieron a los profesores que les enseñaran acerca de los huracanes y los tipos de estrategias y acciones que podían realizarse para garantizar la seguridad, por ejemplo, "enséñame acerca de los huracanes", "dime qué hacer para estar seguro" y "explícame las cosas para que pueda sentirme seguro". Los niños sentían que el gobierno debía construir casas más sólidas y utilizar mejores materiales, además de construir albergues y ofrecer lugares de refugio en tiempos de desastre. Otras peticiones al gobierno incluían ayuda financiera para la reconstrucción y una garantía de que no habría escasez de servicios necesarios (como servicios de salud).

\section{Los niños como investigadores (entrevistadores)}

A los niños por lo general se los subestima en cuanto a la comprensión y articulación de sus propias experiencias. Escucharlos con atención y darles la oportunidad de hablar frente a acontecimientos en sus vidas suele demostrar que esta idea está muy lejos de la verdad. Fue posible notar una comprensión clara de sus experiencias ante el huracán y una claridad en sus cogniciones con respecto a estos acontecimientos en las preguntas que hacían los niños a sus pares durante el primer ejercicio. Además, fueron capaces de responder a las preguntas y relatar sus historias en maneras que demostraban que comprendían lo que había ocurrido, señalando aquellos aspectos de su experiencia que habían sido 
importantes para ellos o que habían tenido un mayor impacto en sus vidas. Ya que los niños estaban entrevistando a otros niños, surgieron elementos en sus historias que podrían haber sido pasadas por alto por un entrevistador adulto. Los niños entrevistadores fueron capaces de involucrarse en las experiencias de los otros de una manera en que un adulto tal vez podría no haber conseguido.

\section{Conclusión e implicaciones para la práctica}

Los hallazgos de la investigación apuntan a diversos temas prácticos:

1. El trabajo grupal es un medio eficaz para trabajar con niños que han vivido algún trauma. La riqueza y los beneficios inherentes del proceso dialéctico y el poder comprender uno del otro son inconmensurables.

2. Al trabajar con esta población, resulta importante adoptar una postura en la que se reconozcan las fortalezas de los niños. Se suele subestimar la capacidad que tienen los niños para lidiar con estas situaciones y recuperarse de ellas y, por tanto, es posible que sus capacidades y fortalezas estén siendo subutilizadas y que no se estén enfocando durante una terapia.

3. Los niños tienen la capacidad de comprender sus experiencias y hablar de ellas y, de hecho, realizan una reestructuración cognitiva relativa al trauma. Sin embargo, por lo general no se los percibe como agentes y son vistos como personas que van en camino a la adultez. Por tanto, debido a su edad y su supuesta inmadurez, se les niega el derecho a hablar por sí mismos, se los desestima o se cree que no son testigos confiables de sus propias experiencias. Esto puede tener repercusiones negativas en el trabajo terapéutico con niños, lo que evita que los profesionales los escuchen, evalúen y utilicen el conocimiento que los niños pueden ofrecer. Por ello, es importante que los profesionales entiendan los puntos de vista de los niños y la comprensión que tienen de sus experiencias, y que descubran sus procesos de reestructuración cognitiva, ya que pueden ofrecer señales claras sobre dónde está el niño y pueden indicar el trabajo a realizar durante la terapia. El desafío para los profesionales es reconocer y aceptar la validez de la voz de los niños $y$, más aun, encontrar maneras en que los niños puedan traer su propio conocimiento para las interacciones terapéuticas y de desarrollo.
4. El uso del proceso dialéctico en esta investigación ha puesto de manifiesto los beneficios de los conocimientos y experiencias compartidas, el aprendizaje resultante y la validez de que los niños ayuden a otros niños. Por ello, puede ser útil desarrollar programas de ayuda a pares en las escuelas y comunidades, como una manera de ayudar a que los niños puedan lidiar con el trauma de situaciones de desastre y puedan desarrollar la resiliencia.

5. Deben realizarse acciones proactivas para enseñar a padres, profesores y tutores cómo apoyar a los niños durante acontecimientos traumáticos como son los desastres naturales. Ayudar a los niños a lidiar con ese tipo de traumas es fundamental para los padres caribeños, especialmente si consideramos que la región tiene una estación de huracanes entre junio y diciembre, año tras año. Ya que la resiliencia de los niños se ve realzada por factores en su entorno, incluyendo las relaciones positivas con sus familias y su comunidad, es importante ayudar a que estas personas claves desarrollen relaciones positivas de afecto con los niños y fomentar la creación de entornos donde los niños sientan que pueden tener una voz y que esta será escuchada. La resiliencia de los niños también puede realzarse mediante la presencia de familia/padres o seres queridos en tiempos de trauma, y esas personas constituyen modelos de conducta que los niños utilizan. Es importante que los profesionales ayuden a que estas personas encuentren maneras de manejar sus propias respuestas afectivas de manera eficaz, y que ayuden a que los padres se conviertan en líderes emocionales de sus hijos.

6. Al trabajar con esta población, resultan útiles las metodologías creativas. Una de ellas es ayudar a que los niños creen diarios de vida de los desastres, donde puedan tener un espacio para registrar sentimientos y acontecimientos, reescribir sus experiencias traumáticas usando cualquier medio; es decir, escribiendo, dibujando, pintando, etc. Esta estrategia puede ser sumamente útil en aquellas sociedades donde se vive bajo el lema "los niños deben verse pero no escucharse", ya que se convierte en un espacio terapéutico de expresividad.

7. Con esta población se pueden utilizar elementos espirituales/religiosos, ya que la creencia en un ser superior y en su protección parece realzarse durante y después de los traumas, y puede tener un impacto positivo en la resiliencia. 
8. Los trabajadores sociales en las escuelas pueden promover foros donde los niños puedan expresarse de manera artística/creativa con respecto a sus experiencias traumáticas, con propósitos terapéuticos y como un modo de celebrar el haber sobrevivido. Este tipo de expresión puede ayudar a que los niños reconozcan sus fortalezas y los mecanismos que han utilizado para lidiar con ese tipo de situaciones.

Los protocolos para el trabajo con niños que han vivido desastres naturales pueden incluir:

1. Los niños deberían participar en actividades de preparación ante desastres. En caso de un desastre natural inminente, los niños deberían estar incluidos en la preparación que hacen sus familias, por ejemplo, recolectando provisiones, protegiendo sus pertenencias personales o empacando un equipo de emergencia. La participación en este tipo de actividades puede ayudarlos a disminuir la ansiedad, ya que el niño puede sentirse reconfortado por el hecho de que está participando en la toma de medidas para garantizar su seguridad y bienestar y la de su familia.

2. A la hora de preparar un equipo de emergencia, se debería permitir que los niños escojan un elemento que los reconforte y les dé seguridad. Es posible que este elemento no cumpla con las normas usuales sobre elementos de un equipo de emergencia, pero darle al niño la opción de hacerlo le otorga una voz en la preparación, aumentando su capacidad de sentirse seguro y reconfortado durante el desastre. Los elementos pueden ser un juguete favorito, un libro o alimentos preenvasados. La preparación de un equipo de emergencia también puede ser una actividad simbólica, ya que representa una caja en la que los niños pueden dejar todos sus miedos y ansiedades, empacándolos y guardándolos. Por ello, puede representar una contención externa de sus sentimientos de confusión y miedo y una llave de acceso al consuelo y la seguridad (mediante algunos de sus elementos escogidos) que puede servir para algunos de estos miedos.

3. Se debería enseñar a los niños acerca de los desastres naturales, es decir, qué son, qué los origina, qué esperar antes, durante y después de un desastre natural y cuáles son las medidas de seguridad que pueden tomarse. El conocimiento es poder, y entregarles a los niños información acerca de estos fenómenos puede ayudarlos a hacer elecciones de manera informada y a que disminuyan en parte su ansiedad, si saben qué esperar.
Algunas maneras que sugirieron los niños de esta investigación para entregarles esta educación fueron: charlas en las escuelas, programas televisivos en los que los protagonistas sean niños, distribución de folletos informativos, programas radiales, anuncios por altoparlantes en las comunidades, folletos y volantes que pueden ponerse en diarios y revistas, artículos en diarios y teatros comunitarios. También sugirieron la creación de un número telefónico para niños, donde podrían recibir información y respuestas a sus dudas y preguntas.

Estatutos legislativos como la Convención sobre los Derechos del Niño de las Naciones Unidas reconocen que los niños no solo necesitan un alto estándar de vida sino que, al garantizarlo, los niños adquieren una voz que es escuchada para poder comprender sus necesidades, derechos y aspiraciones. Los niños son lo suficientemente competentes como para entender y describir su propio mundo después de un desastre, y son los mayores expertos en cómo los niños viven los desastres. Es por ello que se vuelve imperativo a la hora de trabajar con niños que los profesionales y científicos sociales los hagan participar directamente con respecto a sus experiencias. Esta es la única manera en que la experiencia de los niños en los mundos en los que viven y el conocimiento que dicha experiencia otorga, puedan unirse al conocimiento formal de profesionales e investigadores, con el fin de obtener un entendimiento mayor sobre las geografías de los niños. Para poder ayudarlos de mejor manera, en especial después de acontecimientos traumáticos, debemos aprender de ellos y permitir que se obtenga información desde la perspectivas de los niños, aumentando así la validez de el carácter agente de los niños y teniendo un impacto en los monopolios discursivos acerca de ellos, creando posibilidades - "incluso la menor de las posibilidades, por el momento más corto, de ver las cosas de una manera distinta" (Jones en Humphries 2000: 44).

\section{Referencias}

BROCK, S.; LAZARUS, P. y JIMERSON, S. (2002). Best Practices in School Crisis Prevention and Intervention. Bethesda: National Association of School Psychologists.

CUNNINGHAM, J.; WALSH, G; DUNN, J.; MITCHELL D. y MC ALISTER, M. (2004). Giving Children a Voice: Accessing the Views and Interests of Three/ Four year old Children in Playgroup. Revisado el 20 de octubre de 2005 en http://www.dhsspsni.gov.uk/giving_children_voice2.pdf 
GOLDMAN, L. (2004). Raising Our Children to Be Resilient: A Guide to Helping Children Cope with Trauma in Today's World. Revisado el 20 de octubre de 2005 en http://www.childrensgrief.net/resiliency.htm

HENAHAN, S. (2001). Disaster Response. Revisado el 20 de octubre de 2005 en http://www.accessexcellence. org/WN/SU/disaster.html

HUMPHRIES, B. (2000). Research in Social Care and Social Welfare: Issues and Debates for Practice. London: Jessica Kingsley Publishers.

JONES, A. (1998). Exploring Young People's Experience of Immigration Controls: The Search for an Appropriate Methodology in Humphries, Beth (2000). Research in Social Care and Social Welfare: Issues and Debates for Practice. London: Jessica Kingsley Publishers.

LA GRECA, A.; SILVERMAN, W.; VERNBERG, E. y PRINSTEIN, M. (1996). Symptoms of Post Traumatic Stress in Children following Hurricane Andrew: A Prospective Study. Journal of Consulting and Clinical Psychology, 64 (4), 712-723.

MASTEN, A.; BEST, K. y GARMEZY, N. (1990). Resilience and Development: Contributions from the Study of Children Who Overcome Adversity. Journal of Development and Psychopathology (2) (p 425-444).

NORMAN, E. (2000). Resiliency Enhancement: Putting the Strengths Perspective Into Social Work Practice. Nueva York: Columbia University Press.

UNESCO (2000). Guidelines for Education in Situations of Emergency and Crisis. París: UNESCO. 